\title{
Colorectal adenoma and carcinoma specific miRNA profiles in biopsy and their expression in plasma specimens
}

\author{
Zsófia Brigitta Nagy ${ }^{1 *}$, Barnabás Wichmann², Alexandra Kalmár', Orsolya Galamb², Barbara Kinga Barták', \\ Sándor Spisák ${ }^{3}$ Zsolt Tulassay² and Béla Molnár ${ }^{2}$
}

\begin{abstract}
Background: MiRNA expression markers are well characterized in colorectal cancer (CRC), but less is known about miRNA expression profiles in colorectal adenomas. Genome-wide miRNA and mRNA expression analyses were conducted through the colorectal adenoma dysplasia sequence. Furthermore, analysis of the expression levels of miRNAs in matched plasma samples was performed, focusing on biomarker candidates; miRNA and mRNA expression analyses were performed on colorectal biopsies and plasma samples (20 normals; 11 tubular and 9 tubulovillous adenomas; 20 colorectal carcinomas) by miRNA 3.0 and Human Transcriptome Array (Affymetrix) and validated by RTqPCR. Microarray data were analyzed using Expression Console and mRNA targets were predicted using miRWALK 2.0.
\end{abstract}

Results: Based on microarray analysis, 447 miRNAs were expressed in tissue and 320 in plasma. Twelve were upregulated (miR-31, 8-fold $p<0.001$ ) and 11 were downregulated (miR-10b 3-fold $p<0.001$ ) in neoplastic lesions compared to normal group. Eleven miRNAs showed altered expression between adenoma subtypes (miR-183 2.8-fold change, $p<0.007$ ). Expression level of 24 miRNAs differed between adenoma and CRC groups (including miR-196a, 3.5-fold). Three miRNAs (miR-31, miR-4506, miR-452*) were differentially expressed in adenoma compared to normal both in tissue and plasma samples. miRNA expression data were confirmed by RT-PCR both in plasma and matched tissue samples.

Conclusions: MiRNAs showed characteristic expression changes during CRC development in tissue. miRNAs were also presented in plasma and positively correlated with matched tissue expression levels. The identified miRNA expression changes could be verified RT-PCR methods facilitating routine application.

Keywords: microRNA, Colorectal cancer, Colorectal adenoma, miRNA profiling, Microarray, Real-time PCR

\section{Background}

Colorectal cancer (CRC) is the third most common malignant neoplasm worldwide [1]. Adenocarcinoma cells differ from healthy epithelial cells having morphological, epigenetic, and genetic alterations, that are reflected in the altered function of the epithelial cells in the colon. In the classic model of tumorigenesis, CRC develops through polyps to cancer, starting with an early development to adenoma from an aberrant crypt foci followed by colorectal tumor progression. This multistep process is influenced by several

\footnotetext{
* Correspondence: nagyzsofiab@gmail.com

'Molecular Gastroenterology Laboratory, 2nd Department of Internal Medicine,

Semmelweis University, Szentkirályi Str. 46, Budapest 1088, Hungary

Full list of author information is available at the end of the article
}

underlying genetic and epigenetic alterations, as Fearon and Vogelstein proposed [2].

Several studies have examined adenomas the intermediate step of colorectal carcinoma development [3, 4]. As Kinzler and Vogelstein described, tubular adenomas can transform into advanced adenomas with severe dysplasia and a high risk of malignant progression finally evolving to adenocarcinoma [5]. The adenoma-dysplasia-carcinoma sequence has been genetically well evaluated and explored by targeted and whole genome mutation analysis [6].

Analyses of multiple parallel gene expression alterations are providing deeper insights into oncogenic transformation. Several classes of screening targets have been developed in colorectal cancer: proteins [7], DNA [8], messenger RNA [9], and microRNA (miRNA) [10]. Beside mRNAs, 
small RNA molecules are also involved in tumor progression: the miRNAs are 19-23 nucleotide long, non-coding endogenous single-stranded RNAs that function as posttranscriptional gene regulators by binding to their target mRNAs [11]. miRNA expression alterations have been observed in various types of human cancers including breast cancer [12], hepatocellular carcinoma [13], colorectal cancer [14], and lung cancer [15].

Deregulated microRNAs have an important role in progression of colorectal cancer but less is known about their role in premalignant adenomas. Changes in the expression pattern of miRNAs can be informative and highly significant in the colorectal adenoma-carcinoma sequence progression as well. However, to date precancerous lesions (such as adenomas) have been investigated less frequently than cancers compared to healthy tissues $[16,17]$.

Possible miRNA-mRNA interactions can be predicted using in silico prediction methods, that became [18] available using new (computer) algorithms and techniques [19-21] which have made a more detailed analysis and prediction possible [22] and improved knowledge about cancer development.

During colorectal cancer development, release of nucleic acids (DNA, mRNA, miRNA) can be observed in blood in free circulating, protein, and exosome bound forms. Circulating miRNAs can be detected in plasma, as well [23]. Due to the stability of miRNAs, they can be used as stable prescreening molecules in plasma samples, once their sensitivity and specificity is proven. Microarray technology allows characterization of tissue samples by screening the expression level of thousands of genes simultaneously [24]. Recently, several studies have been published using microarray platforms in addition, real-time PCR array methods are already available to enable systematic, whole genome miRNA expression analysis in comparison between normal and tumor samples [4, 25, 26].

To date our research group has screened systematic alterations of DNA methylation [27], mRNA expression [28-30], and protein expression [31] in colorectal cancer development. Furthermore, the Septin 9 plasma methylation marker was also evaluated [32]. Analysis of
miRNAs, as part of an epigenetic regulatory network complements our developing understanding of this complex process.

The aim of the present study was to perform an additional global miRNA microarray analysis of tubular and tubulovillous adenoma biopsy specimen completed with colorectal adenocarcinomas using fresh frozen and FFPE tissue. Changes in miRNA expression patterns were also investigated from plasma samples obtained from the same patients. Furthermore mRNA analysis was also performed using Human Transcriptome Arrays 2.0, to allow integrated investigation of the genome-wide parallel mRNA and miRNA expression changes.

\section{Methods}

\section{Clinical samples}

The study protocol was approved by the local ethics committee (Semmelweis University Regional and Institutional Committee of Science and Research Ethics; Nr.: ETT TUKEB 23970/2011), and written informed consent was provided by all patients. Patients did not receive chemoor radiotherapy prior to sample collection. Clinicopathological features can be found in Additional file 1: Table S1.

Fresh frozen colonic biopsy samples (approx. 3-5 mg tissue specimens) from 20 colorectal cancer 20 normal colorectal, 11 tubular and 9 tubulovillous adenoma tissues were obtained during routine colonoscopy examinations. Tissues were immediately placed in RNALater (Qiagen, cat. no. 76104) and were stored at $-80^{\circ} \mathrm{C}$. FFPE specimens were also collected and processed from parallel surgical tissues. EDTA-stabilized peripheral blood samples were obtained after approved consent (Table 1).

\section{Isolation of total RNA including miRNA from fresh frozen biopsies}

Total RNA including miRNA was isolated from biopsy samples using the High Pure miRNA Isolation Kit (Life Science Roche, cat. no. 05080576001) according to the manufacturer's instruction, after homogenization with MagNA Lyser instrument (Life Science Roche, cat. no. 03358976001). RNA integrity was evaluated using 2100

Table 1 Samples used in the study

\begin{tabular}{|c|c|c|c|c|c|}
\hline \multirow[t]{2}{*}{ Sample types } & \multicolumn{4}{|c|}{ Patients groups } & \multirow[t]{2}{*}{ Methods } \\
\hline & Normal & Tubular adenoma & Tubulovillous adenoma & Adeno-carcinoma & \\
\hline FF tissue biopsy & $n=20$ & $n=11$ & $n=9$ & $n=20$ & Microarray \\
\hline Matched plasma & $n=4$ & $n=4$ & $n=4$ & $n=4$ & Microarray \\
\hline \multirow[t]{2}{*}{ FF tissue biopsy (pooled) } & \multicolumn{4}{|c|}{ Pooled tissue samples } & \multirow[t]{2}{*}{ Real-time PCR } \\
\hline & $\begin{array}{l}n 1=1-10 \\
n 2=11-20\end{array}$ & $n 1=1-11$ & $n 1=1-9$ & $\begin{array}{l}n 1=1-10 \\
n 2=11-20\end{array}$ & \\
\hline Matched plasma & $n=3$ & $n=3$ & $n=3$ & $n=3$ & Real-time PCR \\
\hline FFPET surgical tissue & $n=3$ & $n=3$ & & $n=3$ & Real-time PCR \\
\hline
\end{tabular}


Bioanalyzer (Agilent, cat. no. G2940CA), and RNA yield was quantified using Qubit 1.0 fluorometer (ThermoFisher Scientific).

\section{Total RNA isolation from FFPE specimen}

Hematoxylin and eosin stained sections $(10 \mu \mathrm{m})$ from each formalin-fixed paraffin-embedded tissue blocks were used for histological analysis.

Three tissue sections were cut from standard formalinfixed paraffin-embedded blocks and were transferred to a microcentrifuge tube per isolation. Deparaffinization was performed with $1 \mathrm{ml}$ xylene for $10 \mathrm{~min}$ twice and washing with $1 \mathrm{ml}$ absolute ethanol for $10 \mathrm{~min}$ twice. miRNAs were isolated from three air-dried deparaffinized sections per isolation using the High Pure miRNA Isolation Kit.

\section{miRNA isolation from plasma specimen}

Peripheral blood samples were drawn into EDTAcontaining tubes and centrifuged at $1350 \mathrm{rpm}$ for $12 \mathrm{~min}$ at $24{ }^{\circ} \mathrm{C}$ (room temperature). The supernatants were then centrifuged with the same parameters in a second round. The plasma samples were stored at $-20{ }^{\circ} \mathrm{C}$ until use. The miRNA fraction was extracted using the QIAamp Circulating Nucleic Acid Kit (Qiagen, cat. no 55114) with the following protocol: $1 \mathrm{ml}$ of plasma was mixed with $100 \mu \mathrm{l}$ proteinase K (Qiagen, cat. no. 55114) and $800 \mu \mathrm{l} \mathrm{ACL} \mathrm{buffer}$ (Qiagen, cat. no. 55114), and samples were incubated at $60^{\circ}$ $\mathrm{C}$ for $30 \mathrm{~min}$. Then $1800 \mu \mathrm{l}$ ACB Buffer (Qiagen, cat. no. 55114) and $3 \mathrm{ml}$ isopropanol were added to the mix, and the tubes was gently inverted a few times. Tubes were then incubated at $-20^{\circ} \mathrm{C}$ overnight. The mixture was filtered through the column followed by washing steps with $1 \mathrm{ml}$ $70 \%$ and $1 \mathrm{ml}$ absolute ethanol. RNA was eluted in $30 \mu \mathrm{l}$ puffer AVE (Qiagen, cat. no.55114).

\section{Tissue and plasma miRNA microarray and mRNA} expression profiling by Human Transcriptome Array 2.0 The miRNA expression profiles were analyzed by GeneChip miRNA 3.0 array (Affymetrix, cat. no.902413). $1 \mu \mathrm{g}$ of total RNA including miRNA from tissue, and the total amount of eluted miRNA fraction from plasma samples were biotin-labeled using the Flashtag Biotin HSR RNA Labeling Kit (Affymetrix, cat. no.901911). The samples were hybridized for $16 \mathrm{~h}$ in a GeneChip Hybridization Oven 645 (Affymetrix, cat. no. 00-0331), then were washed and stained using a GeneChip Fluidics Station 450 (Affymetrix, cat. no. 00-0079) with the FS450_0002 fluidics protocol and scanned with a GeneChip ${ }^{\circ}$ Scanner 3000 7G (Affymetrix, cat. no.00-0210).

Out of the 60 fresh frozen biopsy tissue samples, 20 (7 normal, 2 tubular, 4 tubulovillous adenoma, and 7 tumor) were selected for mRNA expression analysis using a GeneChip Human Transcriptome Array 2.0 (Affymetrix, cat. no.902162) according to the manufacturer's instructions.
Real-time quantitative PCR array analysis from fresh frozen and individual FFPE tissue specimen

$40 \mathrm{ng}$ of total RNA including miRNA was reverse transcribed using the miRCURY LNA ${ }^{\mathrm{m}}$ Universal RT cDNA Synthesis Kit (Exiqon cat. no. 203301). The cDNA template was then amplified using the microRNA Ready-to-Use PCR, Human Panel I+ II (Exiqon) in 384-well plates according to the manufacturer's instruction. The qPCR reactions were run on a LightCycler 480 System (Life Science Roche) using the thermal-cycling parameters recommended by Exiqon (Denaturation at $95{ }^{\circ} \mathrm{C} 10 \mathrm{~min}, 45$ amplification cycles at $\left.95{ }^{\circ} \mathrm{C} 10 \mathrm{~s} 60{ }^{\circ} \mathrm{C} 1 \mathrm{~min}\right)$. The amplification curves were analyzed by LightCycler 480 Software (Life Science Roche, cat. no. 04994884001). From the 768 wells, 742 miRNA primer sets were used for miRNA expression profiling, there remaining wells contained interplate calibrator oligonucleotides, spike-in control oligonucleotides, and empty wells. Hsa-miR-423-5p was used for normalization. The relative quantification of miRNA expression levels was performed using delta deltaCp method [33].

\section{In silico miRNA-mRNA target prediction}

Three miRNA were selected: miR-31 has the highest fold change in normal vs. adenoma normal vs. CRC comparison; miR-4417 and miR-497 were one of the continuously upregulated or downregulated miRNAs in adenomacarcinoma transition and their mRNA targets were predicted using five algorithm: TargetScan, miRanda, PICTAR2, RNAHybrid and miRWalk on miRWalk 2.0 platform. Using DAVID tools (The Database for Annotation, Visualization and Integrated Discovery v6.7) we acquired pathway enrichment from gene ontology. Through the KEGG pathway databases, we examined the pathway target enrichment $(p<0.01)$ of selected groups of miRNAs according to Yin et al. [34].

\section{Immunohistochemistry}

Immunohistochemistry for Cyclin D1 was performed on formalin-fixed and paraffin-embedded tissue samples from normal $(n=15)$ adenoma $(n=15)$ and CRC $(n=10)$ patients (all samples diagnosed in H\&E serial sections by an expert pathologist). Following deparaffinization and rehydration, microwave-based antigen retrieval was performed in TRIS EDTA buffer (pH 9.0) (900 W/10 min, then $340 \mathrm{~W} / 40 \mathrm{~min})$. Samples were immunostained with Cyclin D1 monoclonal antibody (clone SP4: Histopathology Ltd., Hungary, cat no. 10074, 1:100 dilution) and diaminobenzidine-hydrogen peroxidase-chromogen substrate system (HISTOLS-DAB, Histopathology Ltd., cat. no. 30014.K) were used. Slides were digitalized by Pannoramic 250 Flash II scanner (3DHISTECH Ltd.), and digital slides were semi-quantitatively analyzed with Pannoramic Viewer (ver.:1.15.3; 3DHISTECH) based on $Q$ score method (scored by multiplying the percentage of positive cells $(\mathrm{P})$ by the intensity $(I:+3,+2$, 
$+1,0$ ). Formula: $Q=P \times I$; maximum $=300$ ). Primarily we examined separately the epithelial and stromal compartments, then summarize $(\Sigma)$ these scores $(\Sigma \mathrm{Q}$ score maximum: 600) in order to remain comparable with our miRNA and mRNA expression analyses using whole biopsy samples.

\section{Statistical analysis}

Probe cell intensity files of microarrays were analyzed using Expression Console Software (Affymetrix). The robust multichip averaging (RMA) algorithm was used for background correction normalization and probe level summarization. GeneChip miRNA 3.0 array contains probe sets for 1733 mature miRNAs. Human Transcriptome Array 2.0 files were analyzed using Expression Console Software and Transcriptome Analysis Console (Affymetrix). Values of $p<0.05$ were considered as statistically significant with a $\log \mathrm{FC}>|1|$.

\section{Results}

Identification of expressed miRNAs in diagnostic groups

The absolute numbers of expressed miRNAs in the analyzed sample groups were determined based on the intensity values of oligonucleotide probes for 1733 human mature miRNAs that are synthesized on the surface of GeneChip miRNA 3.0 arrays. Present values (based on hybridization) were calculated by Expression Console Software (Affymetrix) using the statistical present/absent calls method.

From the 1733 mature miRNA probe sets, 442 had positive values in normal tissue samples, 460 present values were detected in adenoma (tubular and tubulovillous) tissue samples, and 441 present values were detected in colorectal carcinoma tissue samples (Fig. 1). There were no significant differences in detection calls between the diagnostic groups. The present/absent calls in matched plasma samples from the same diagnostic groups were also observed, 306 miRNAs were observed in the plasma of normal subjects, 334 miRNAs in the plasma of adenoma patients, and 321 miRNAs in the plasma of patients with colorectal cancer (Fig. 1).

\section{miRNA expression in different patient groups Microarray analysis}

miRNA microarray analysis was performed on biopsy tissue samples from healthy patients and also from patients with tubular or tubulovillous adenoma or colorectal cancer. Along the colorectal adenoma-carcinoma transition, based on our microarray profiling 19 continuously upregulated or downregulated miRNAs were selected (Fig. 2). Expression elevation could be observed in case of miR-4417 which was upregulated 2.8-fold in adenoma compared to normal samples, moreover, this expression level was further elevated (1.9-fold) in CRC samples. Interestingly, miRNA-378 family (-i;-f;-e;-g;-*) members are represented highly in downregulated groups of miRNAs. Eight (without miR-378 variants) downregulated miRNAs showed approx. 1.4-2.4-fold lower expression in adenomas compared to healthy, and reduction was $1.5-3$-fold lower in carcinoma samples (Fig. 2).

Figure 3a represents a heatmap of microarray data describing the miRNA expression profiles in precancerous and neoplastic lesions vs. normal samples. Twenty-three miRNAs (11 downregulated and 12 upregulated) were significantly differentially expressed in healthy normal colonic tissue vs. precancerous and neoplastic lesions. The expression of all 12 upregulated miRNAs were increased at least 2-fold in tissues from the normal-adenoma-carcinoma sequence progression. The highest miRNA expression alteration was observed in case of miR-31 showing eightfold higher expression both in adenoma and in CRC tissue compared to normal samples (Additional file 2: Table S2).
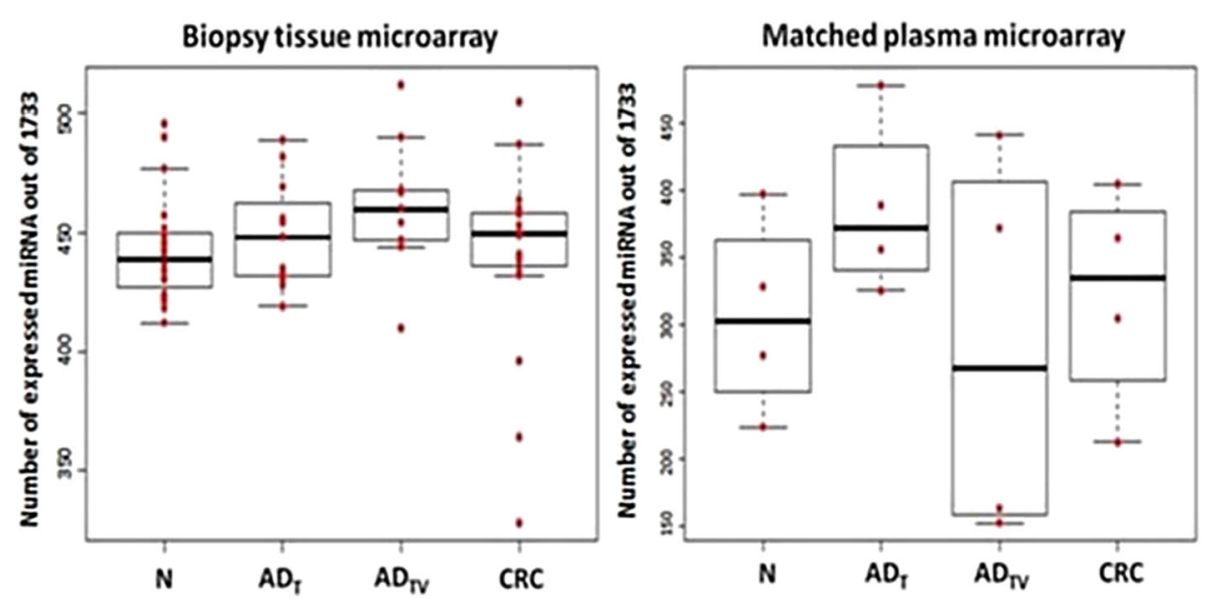

Fig. 1 Number of miRNAs (considered as present) expressed in tissue and plasma samples. $N$ normal; $A D_{\text {tub }}$ tubular adenoma; $A D_{\text {tubvill }}$ tubulovillous adenoma; CRC colorectal cancer 


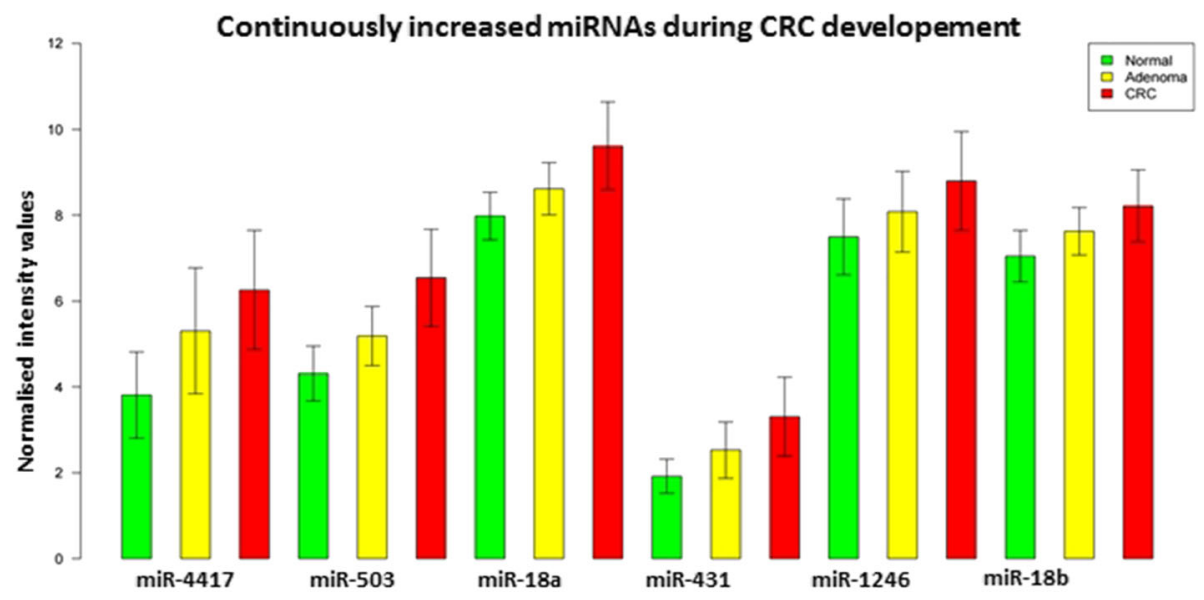

Continuously decreased miRNAs during CRC developement

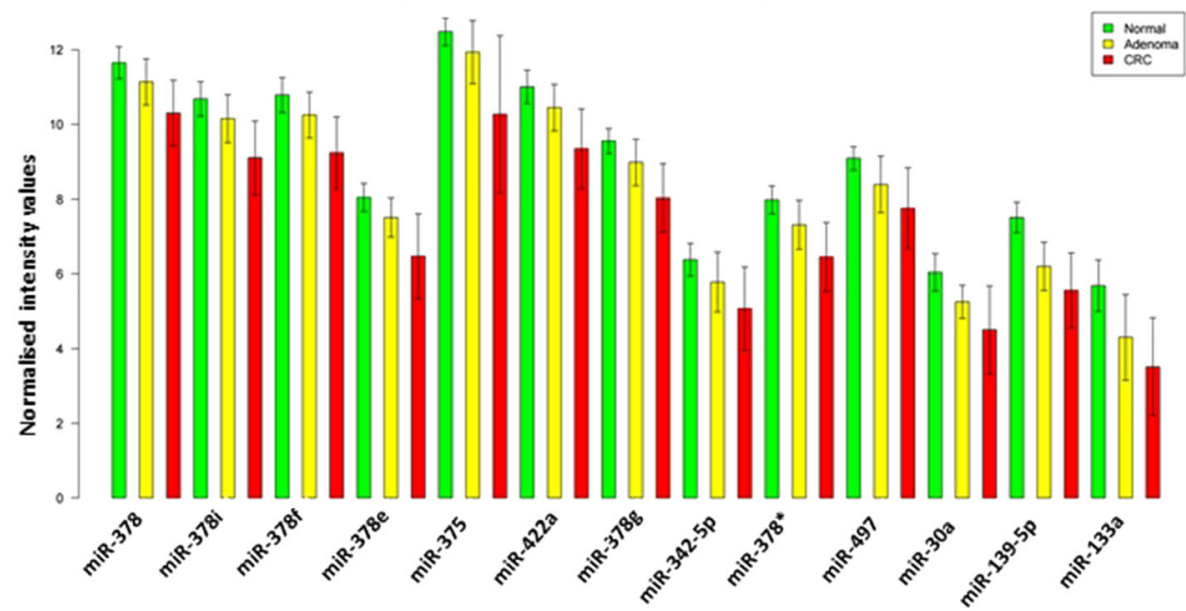

Fig. 2 Bar charts showing the continually upregulated and downregulated miRNAs during cancer progression based on microarray data in tissue samples. Green color represents healthy tissues, yellows are adenomas, red colors are colorectal cancer samples $(p<0.05$, logFC $>\mid 0.5) \mid$

24 miRNAs showed characteristic differences between adenoma and colorectal cancer samples. Only five miRNAs were upregulated in colorectal cancer compared to adenoma (Fig. 3b).

When we selected miRNAs to characterize tubular vs. tubulovillous adenoma, 11 miRNAs showed altered expression between the adenoma subgroups. miR-489 expression showed the greatest difference between adenoma subtypes with a $>4.5$-fold increase in tubulovillous adenoma samples. The fold change of other miRNAs with significantly altered expression were in the range of 2-4 (Fig. 3c).

By the analysis of microarray data, 12 differentially expressed miRNAs could be detected between different stages of colorectal cancer (Fig. 3d). The majority of miRNAs showed overexpression in Dukes D stage samples. Interestingly, members of miR-378 family were highly represented in this comparison, as well as in the groups with continuously changing expression in adenoma to carcinoma progression.
Interestingly, most of the differentially expressed miRNAs in the adenoma-CRC comparison were upregulated in adenomas compared to CRC samples (Fig. 3b). Therefore, we focused on these adenoma-specific miRNA groups and selected those ones which are upregulated in adenomas but after significantly downregulated in CRC patients. Figure 4 represents four miRNAs showing the highest overexpression in adenoma samples. Levels of miR-182, miR-183*, miR-96, and miR-34a are decreased 1.5-fold or higher in carcinoma tissue samples compared to adenoma.

\section{miRNA microarray validation}

In order to confirm the accuracy and reliability of the microarray data, the same tissue/RNA samples as used in miRNA microarray analysis were analyzed using the miRCURY Human Panel real-time PCR (Exiqon) containing 742 mature miRNA oligonucleotides. RT-PCR validation was done on four tissue samples pooled (with equal ng of RNA of the samples in each group) according to the 

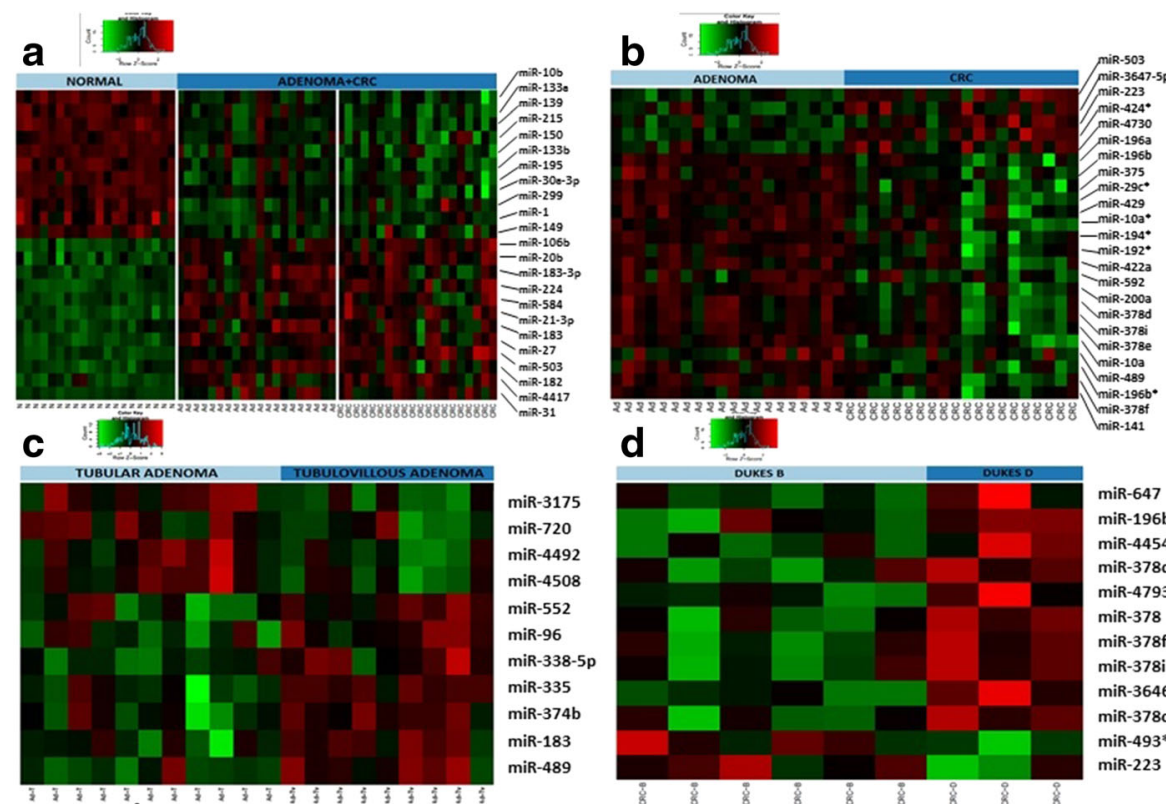

\section{d}
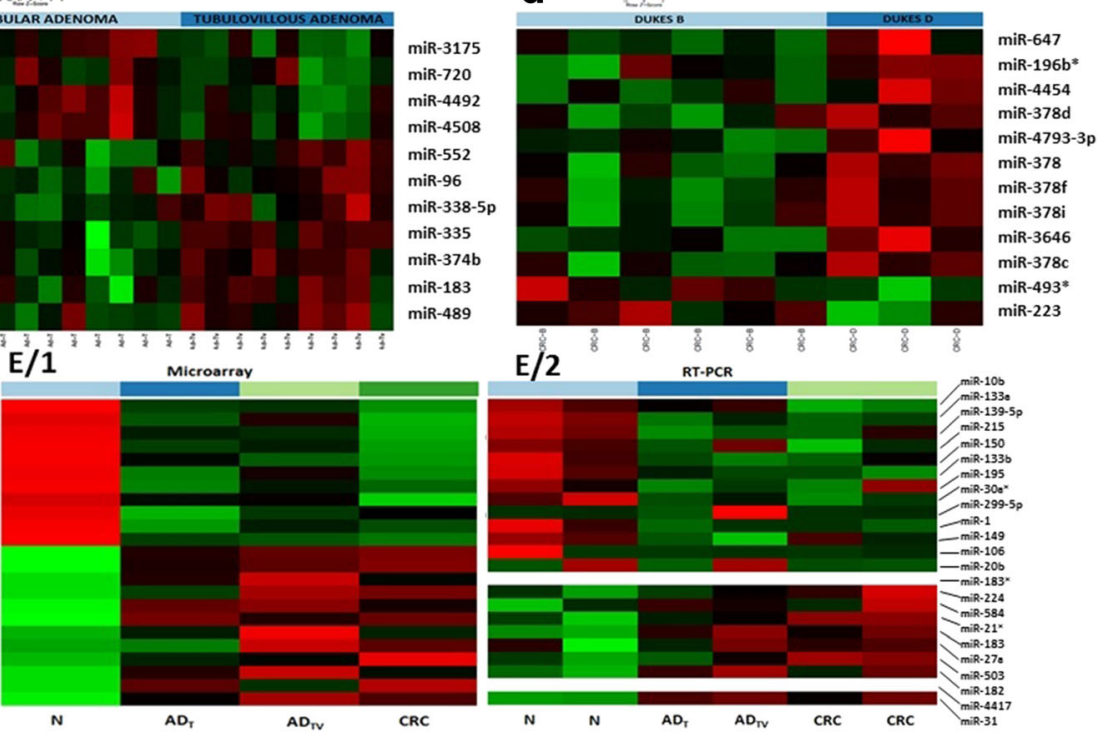

Fig. 3 a Heatmap showing differential miRNA expression in diseased vs normal control group. Green color indicates lower than mean intensity, and red represents higher than mean intensity. Each row represents a miRNA and each column represents a sample $(p<0.05, \log F C>\mid 1) \mid$. $\mathbf{b}$ Comparison of tubular and tubulovillous adenoma with colorectal cancer tissue samples. Each row represents a miRNA. Each column represents a tissue sample. Selected miRNAs are sorted by statistical conditions: $p<0.05, \log F C>|1|$. c Comparison of tubular and tubulovillous adenoma samples. Each row represents a miRNA. Each column represents a tissue sample. Selected miRNAs are sorted by statistical conditions: $p<0.05$, $\log F C>|1|$. d Cluster analysis of Dukes B and D stages. Results based on three miRNAs showed significant expression alteration between groups $(p<0.05)$. e Real-time PCR (E/2) validation of microarray $(E / 1)$ results in fresh frozen biopsy tissue samples. $N$ normal; $A D$ tubular adenoma; $A D_{T V}$ tubulovillous adenoma; CRC colorectal cancer

analyzed diagnostic groups (normal, CRC, tubular adenoma, and tubulovillous adenoma).

miRNAs showing altered expression in precancerous and cancerous lesions by microarrays were selected, and the expression tendencies were detected by real-time PCR validation (Fig. 3e). The results of the analysis confirmed the majority of our microarray data, except for six miRNAs: miRNA-4417 was not represented in the PCR panels, miRNA-183* assay did not give any signal, and four miRNA assays including miR-299-5p, miR-20b, miR-195, and miR215 had outlier signals in pooled PCR patient groups.

\section{miRNA target prediction and validation on Human Transcriptome Arrays}

Based on the Human Transcriptome Array 2.0 mRNA expression results, downregulated mRNA targets were selected. Three miRNAs were selected: miR-31 has the highest fold change in normal vs. adenoma, normal vs. CRC comparison; miR-4417 and miR-497 were one of the continually upregulated or downregulated miRNAs in adenoma-carcinoma transition. mRNA targets were predicted on miRWalk 2.0 platform in silico. Parallel analysis on Human Transcriptome Arrays representing > 245,000 coding transcripts was performed. The selected mRNA targets of the miRNAs can be seen on Fig. 5 . The mRNA expression pattern was observed inverse compared to the miRNA expression pattern.

\section{Deregulated miRNAs' biological function and pathway analysis by KEGG and GO database}

Target genes of the continuously overexpressed and underexpressed miRNAs during CRC development 


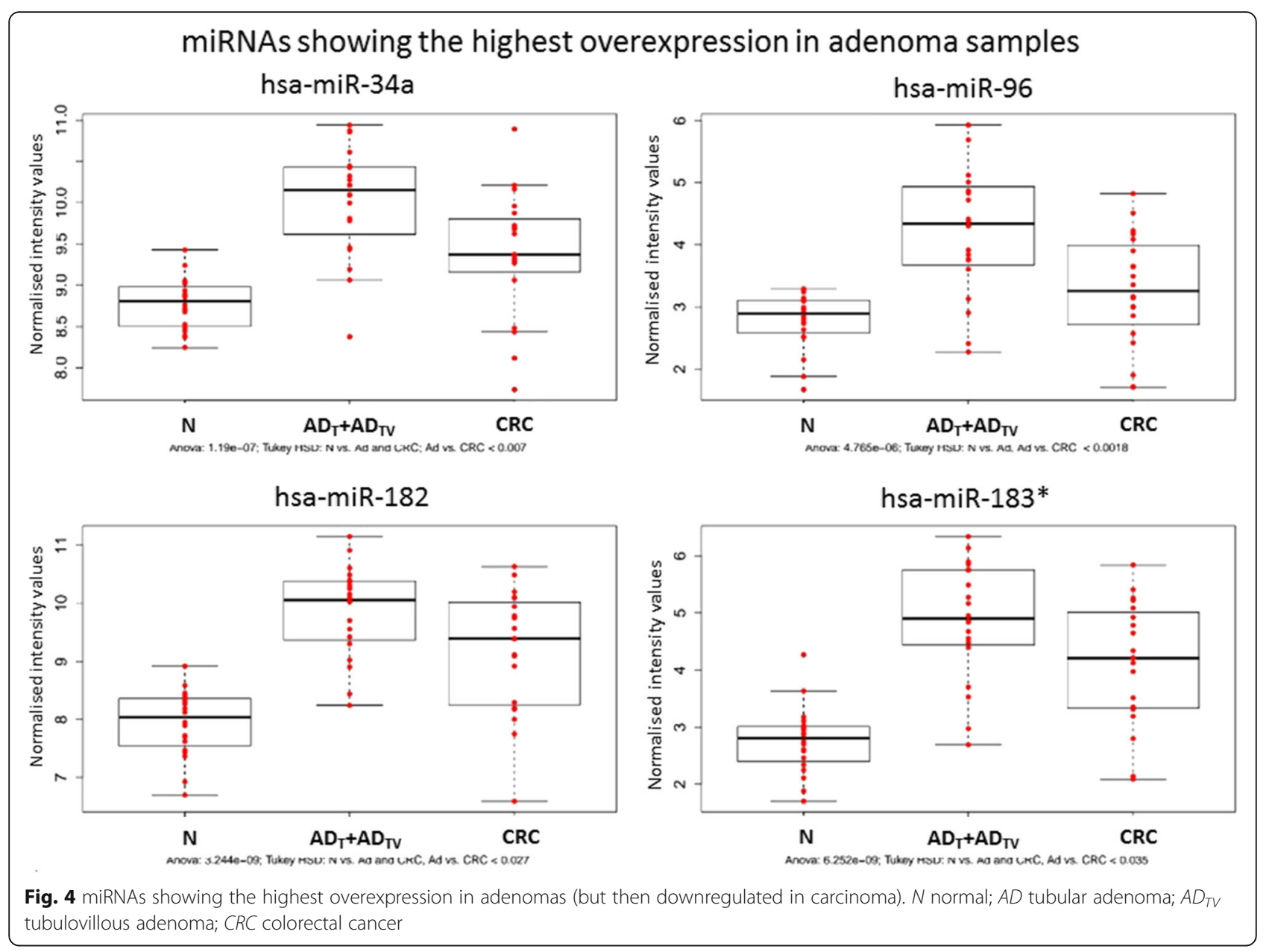

(without miR-378 homologues) (Fig. 2) participate in pathways related to signal transduction (PI3K-Akt KEGG pathway ID: hsa04151, MAPK-KEGG pathway ID: hsa04010) and cancer (KEGG pathway ID:hsa05200) from the top 24 selected KEGG pathways. GO analysis was also conducted on these miRNAs revealing transcription regulations and cell proliferations. (Additional file 3: Tables S3 and S4). Target genes of four miRNAs showing the highest expression in adenomas (Fig. 4) could be related to the following pathways: microRNAs in cancer (ID: hsa05206), pathways in cancer (ID: hsa05200) (Additional file 3: Tables S7 and S8). These predicted genes are involved mostly in DNA transcription regulation and cell proliferations.

\section{Analysis of fresh frozen tissue samples and FFPE surgical samples by real-time PCR}

Delta $\mathrm{Cp}$ values of pooled fresh frozen tissue samples and FFPE tissue samples were visualized on graphs (Fig. 6). The expression of most miRNAs slightly correlated in fresh frozen and FFPE tissue types. These miRNAs could be abundant and are less affected by tissue processing (miR-135b, miR-196b, miR-31). There were some miRNAs whose expressions were more influenced by the sample processing types (FF or FFPE). Expectedly, miRNAs can be isolated more efficiently from fresh frozen samples than from paraffin embedded tissues, however, about more than $60 \%$ (N-67\%, A-65\%, CRC-71\%) of miRNAs expressed in FFPE tissues. Interestingly, among the 742 miRNAs represented on the Exiqon $\mathrm{Hu}$ man Panel I + II PCR plates, 50\% (N-44\%, A-44\%, CRC$48 \%$ ) could be detected only in fresh frozen samples but not in FFPE tissues.

\section{Microarray results of matched plasma samples}

To investigate the clinical potential of miRNAs detected in tissue, plasma samples were collected from the same patients and miRNA microarray analysis was performed. Four miRNAs were found to be expressed in both tissue and plasma samples moreover, in each sample type the selected miRNAs showed the same expression tendency with miRNAs showing altered expression between diagnostic groups (visualized by boxplots) (Fig. 7). 


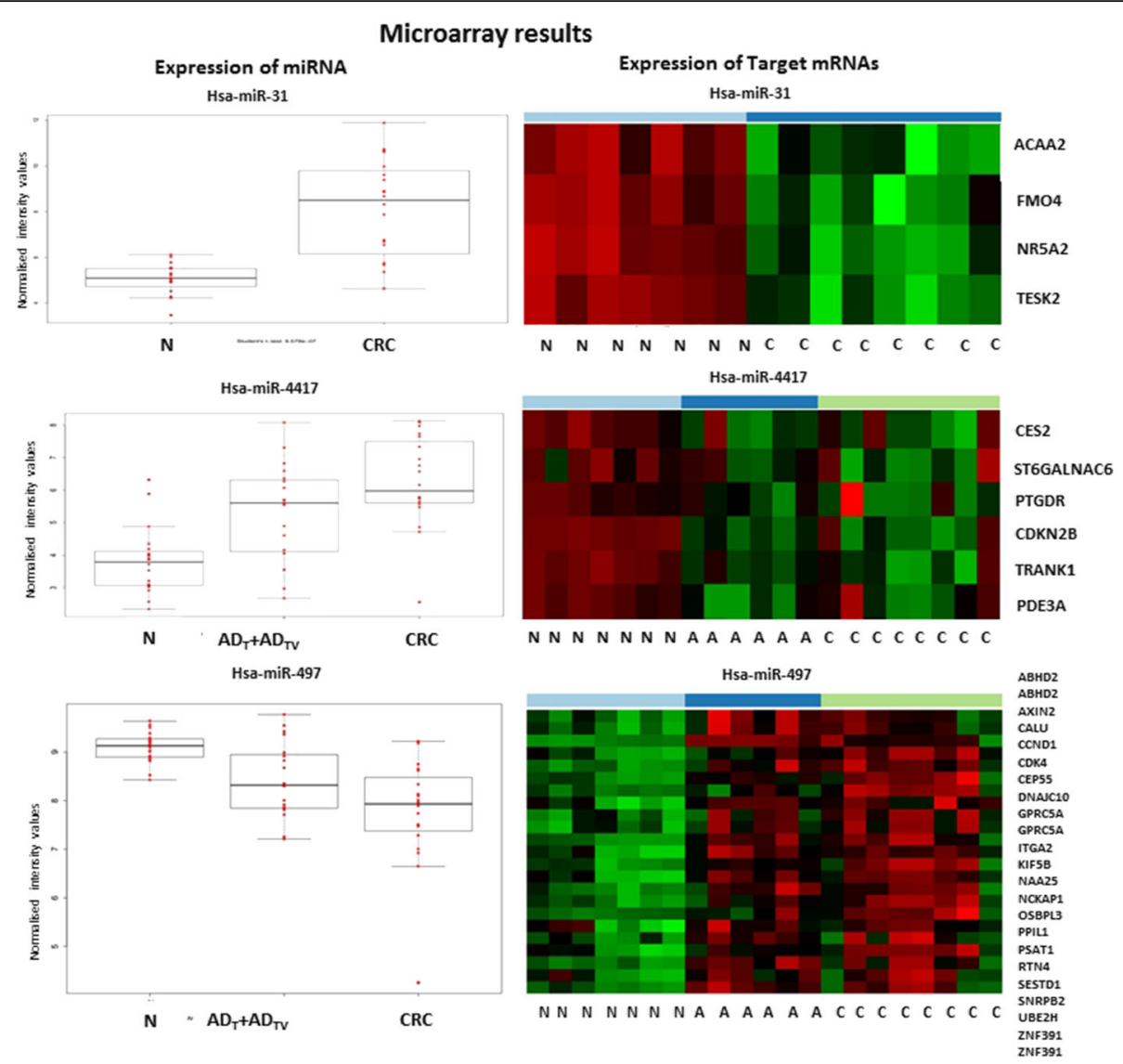

Fig. 5 Selected miRNAs with continuous expression alteration along the colorectal adenoma-carcinoma sequence. Left box plots represent the miRNA expression in tissues. Heatmaps represent the target mRNA expression in tissues. $N$ normal; $A$ adenoma; $C R C$ colorectal cancer. (see full names of genes are in list of Abbrevations)

\section{Immunohistochemistry of Cyclin D1}

The normal epithelium showed low nuclear Cyclin D1 expression (representative scoring values: $0 ;+1 ; Q$ score: $26.66 \pm 8.16)$, whereas among all stromal cells only few showed strong immunoreaction, $(+2$ and +3$)$ $(Q$ score: $12.67 \pm 3.19$ and $\Sigma \mathrm{Q}$ score: $39.32 \pm 8.63$; Fig. 8a). The stromal protein expression was low, but significantly $(p<0.05)$ increased in adenomas $(Q$ score: $17.50 \pm 5.77)$ and in CRCs ( $Q$ score: $19.00 \pm 7.34)$. Heterogenic, significantly $(p<0.05)$ increased nuclear Cyclin D1 expression (representative scoring values: +2 ; $+3)$ was detected in epithelial compartment of adenomas ( $Q$ score: $80.00 \pm 17.88$; Fig. $8 b$ ) and CRCs $(Q$ score: $129.50 \pm 45.85$; Fig. $8 \mathrm{c}$ ). The detailed $Q$ scores of examined sample groups are illustrated on (Fig. 8d).

The detected total protein level alteration along the adenoma-carcinoma transition of the analyzed colorectal tissue samples was fundamentally constituted by the increased epithelial cyclin D1 expression (adenoma $\Sigma \mathrm{Q}$ score: $96.25 \pm 18.75$ and CRC $\Sigma$ Q score: $147.00 \pm 48.94$. ( $\mathrm{N}$ vs. Ad and Ad vs. CRC: $p<0.05)$ ).

\section{Discussion}

In this study, we have carried out a high throughput screening of microRNA expression alterations by microarray analysis in tubular, tubulovillous colorectal adenoma, and adenocarcinoma samples. Healthy colonic tissue samples and parallel plasma samples were also evaluated from the same patients. The numbers of expressed miRNAs between the different patients groups are nearly balanced, although less miRNAs were expressed in plasma samples compared with matched tissue samples (approximately 300-330 miR$\mathrm{NAs}$ /samples group). Slattery et al. also found less than 600 expressed miRNAs in colonic tissues on a different microarray platform (Agilent) [3]. Leidinger et al. found that average number of detected miRNAs in control plasma samples was 331, and the overall number of detected miRNAs in plasma of lung cancer patients was between 264 and 364 from a set of 1205 miRNAs analyzed [35].

Genome-wide miRNA expression-profiling studies using high throughput technologies frequently apply comparisons of normal-adenoma or normal-carcinoma pairs (Additional file 1: Table S1). Here, we have performed a 

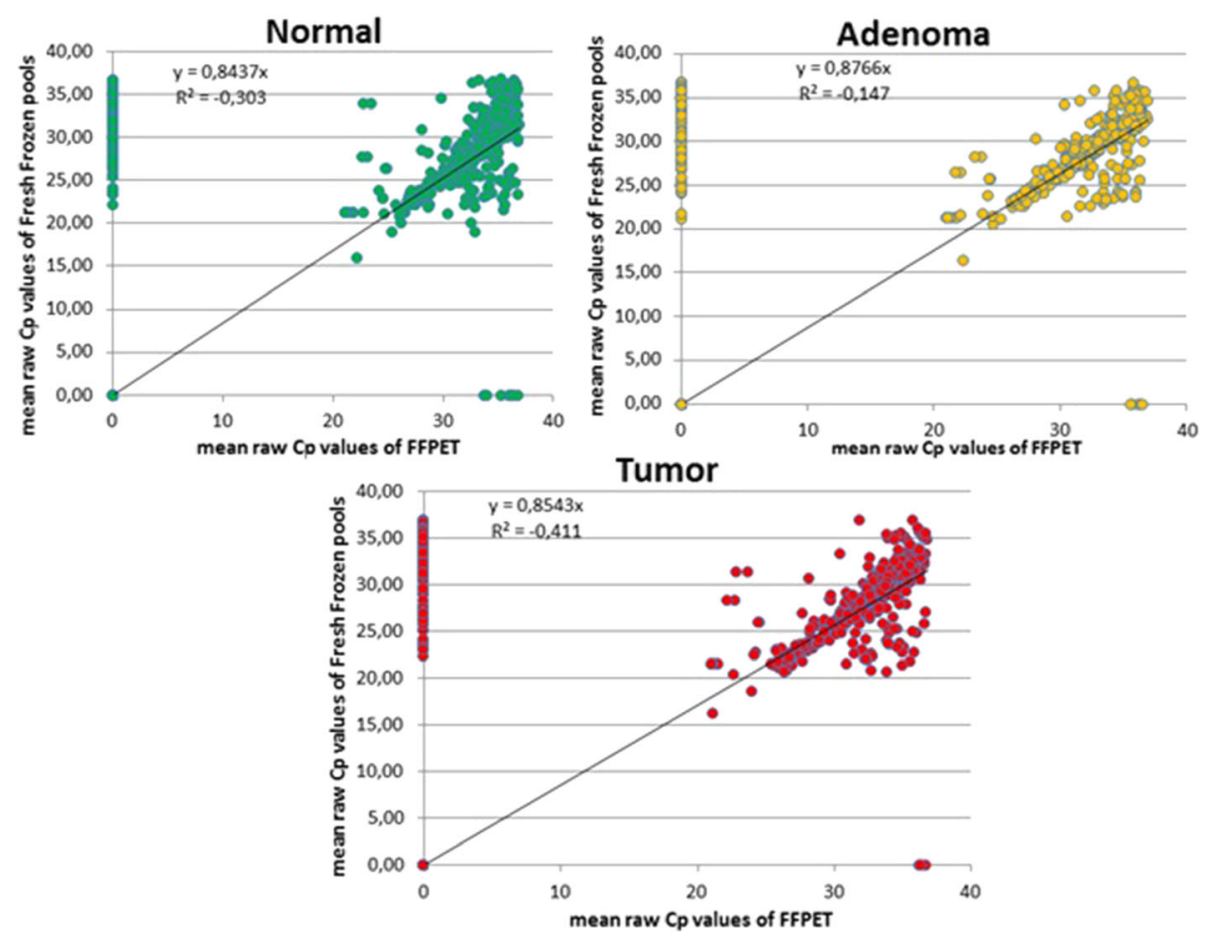

Fig. 6 Correlation between miRNA expression in formalin-fixed, paraffin-embedded (FFPE), and fresh frozen (FF) colonic tissue. dCP values were illustrated in graphs. Axis of $X$ contains all the detected raw $C p$ values of each miRNA in case of FFPE tissues, axis of $Y$ contains all the detected raw $C p$ values in case of fresh frozen tissue samples

comparison of control normal vs. precancerous and neoplastic lesions (adenomas and tumor samples). We have focused on those short RNAs which are continuously upregulated or downregulated through adenoma-carcinoma progression. The continuous downregulation observed in adenoma-carcinoma samples in case of miR-375, miR378, miR-139-5p, miR-133a, and miR-422a was confirmed by others [36-44]. MiR-378 could inhibit tumor growth and invasion partly by targeting vimentin in colorectal cancer [39]. Functional analysis of miR-133a revealed that it can inhibit CRC cell growth and metastasis by targeting LIM and SH3 protein. It represses the MAPK pathway as well, as shown after predicted KEGG pathway analysis [43]. Lower expression of miR-422a was associated with advanced stages of colorectal cancer thus proving its tumor suppressive role [44].

MiR-503 and five other miRNAs (miR-4417, miR-18a, miR-431, miR-1246, and miR-18b) were the only short RNAs, which showed significant upregulation through the normal to adenoma (dysplasia) transition in our analysis. Selected miRNAs have a role in tumor progression, as e.g., miR-503 directly targets L1 adhesion molecule (L1CAM) [45] and E2F transcription factor 3 (E2F3) [46] mRNAs involved in tumor progression. Out of the four adenoma-specific miRNAs (miR-34a, miR-96, miR-182, miR-183*) miR-96, miR-182 expression changes were proven in adenoma and carcinoma samples by Wang et al. in a deep sequencing study with a real-time PCR validation [47]. Furthermore, miR-182 has been reported to suppress ENTPD5 expression which is involved in energy metabolism. Previously, a decreased expression of ENTPD5 mRNA and protein levels was observed during adenoma carcinoma transition [48, 49].

In our study, strong emphasis was placed on exploration of altered miRNA expression patterns in the early benign lesions including the comparison of different adenoma subtypes. Among others, we observed $>$ twofold decreased expression of miR-3175, miR-720, miR4508 and miR-4492 in tubulovillous adenoma compared to tubular adenoma samples. Of interest, miR-3175 expression was also reported to be reduced in gastric adenocarcinoma cell line [50]. Interestingly, elevated miR-720 levels were found in both adenoma subtypes compared to healthy tissue samples. However, expression levels also differed significantly between adenoma subgroups. Nevertheless, an early increasing expression of miR-720 was observed through normal to adenoma transformation, its concentration was more than 2-fold lower in tubulovillous compared to tubular adenoma tissues. Schopman et al. reported that miR-720 is not a classic miRNA, but rather a fragment of a tRNA [51]. It is also known as a novel serum biomarker of CRC [52]. 

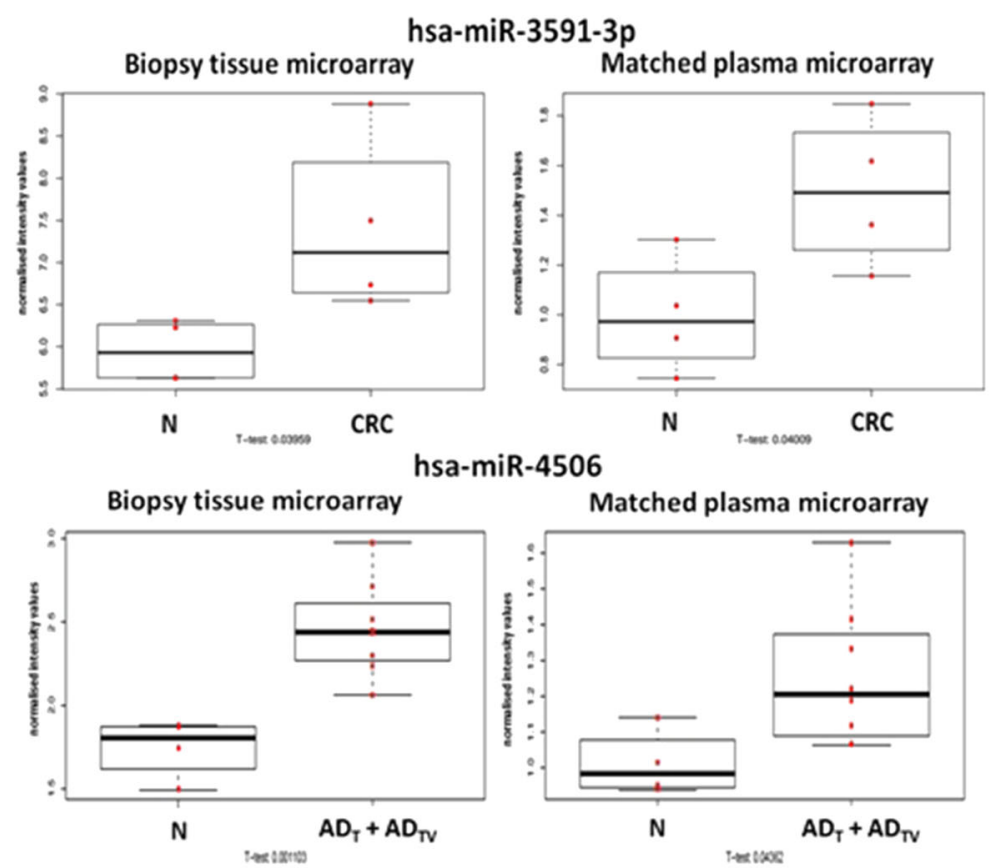

hsa-miR-31
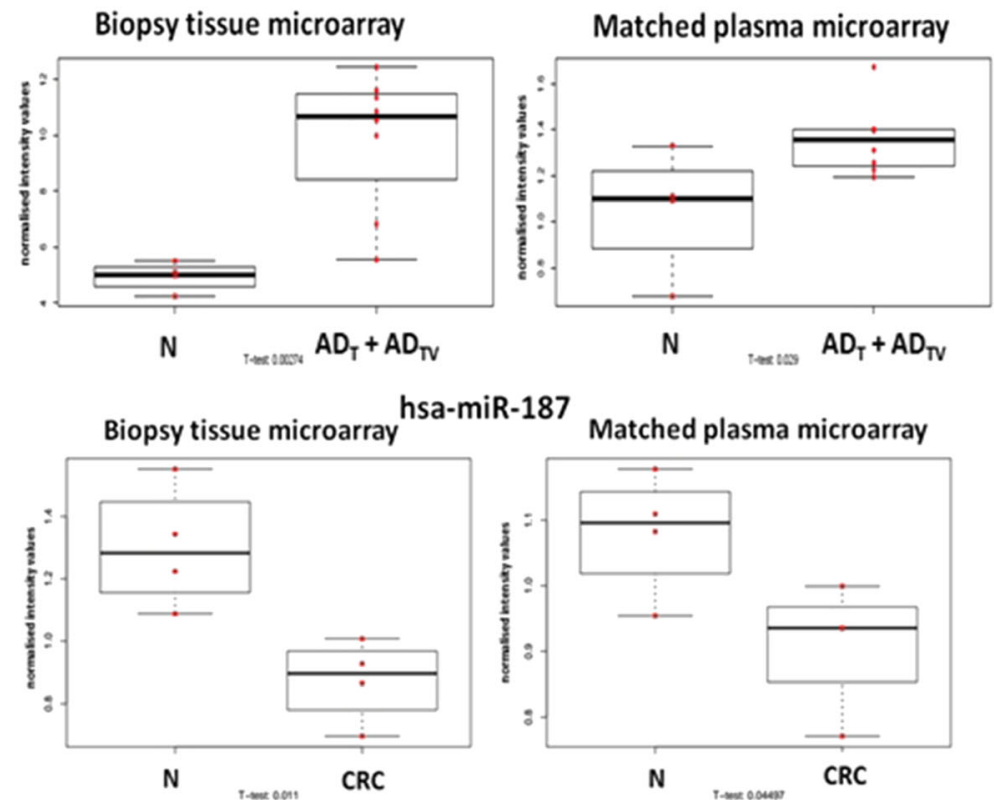

Fig. 7 miRNA expression shows the same tendency in tissue and plasma samples. $N$ normal; $A D$ tubular adenoma; $A D_{T V}$ tubulovillous adenoma; CRC colorectal cancer

Interestingly, miR-489 was found to be the most overexpressed miRNA between adenoma subtypes though its downregulation was observed in CRC and was also associated with other tumor types (Additional file 1: Table S1) $[53,54]$. From the 24 miRNAs which could differentiate between adenoma-carcinoma, the overexpressed miR-223 was a validated oncomiR in CRC invasion and metastasis [55].
In this study, we also demonstrated that miRNA detection efficiency differed in distinct sample types such as fresh frozen and FFPE samples. Interestingly, more miRNA signals could be observed in FFPE than in fresh frozen tissues. Differences in the optimization of isolation protocols or application of pooled samples in case of fresh frozen tissues could cause this phenomenon. 


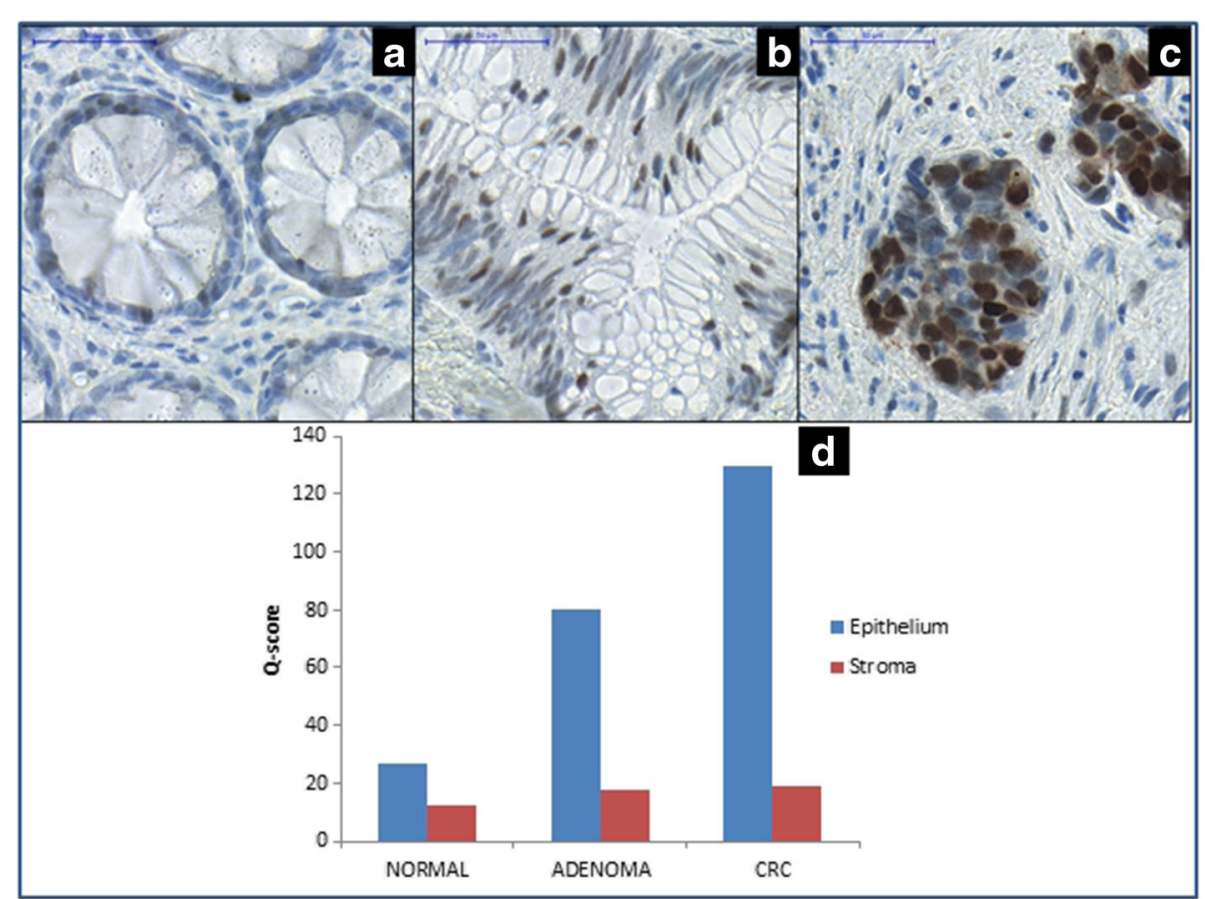

Fig. 8 The expression of Cyclin D1 in normal epithelium (a), adenoma (b), and CRC (c) samples. Digital microscopic image; 50x magnification; scale bar: $50 \mu \mathrm{m}$. The detailed $Q$ scores of examined sample groups are illustrated (d)

We also analyzed the appearance of tissue miRNA expression changes in peripheral blood. In case of several miRNAs, a positive correlation was found between their expression in tissue and plasma samples. miR-187 was downregulated in colorectal cancer compared to normal controls, and its decreased expression tendency could also be detected in the plasma of CRC patients compared with healthy control patients. In a similar way, downregulation of miR-187 has been shown in renal cell carcinoma both in tissue and in plasma samples [56].

In silico target prediction of selected miRNAs, such as miR-31 and miR-4417 which are upregulated in tumor samples $[57,58]$, revealed a set of potential target mRNAs including Flavin containing monooxigenase 4 (FMO4), cyclin dependent kinase inhibitor 2B (CDKN2B), and prostaglandin D2 receptor (PTGDR), whose expression pattern changed oppositely according to our (Human Transcriptome Array 2.0 microarray) results. FMO4 is influenced by miR-31. FMO4 catalyzes NADPH-dependent oxidative metabolism and is downregulated in carcinoma cells by miR31 [59]. Among the targets of miR-4417, PTGDR is downregulated in CRC which can be caused by promoter hypermethylation, as well [60].

"Previous studies reported that the highly conserved miR-195/497 cluster was significantly downregulated in gastric, breast, bladder, liver, and also in colorectal cancer [61-66]. Although, our investigation was limited to determine the expression level of miR-497 and its predicted target, CCND1 mRNA and protein level according to several functional analyses - such as luciferase assay-based methods - carried out in different types of cancers revealed that miR-497 (and miR-195) directly targets the 3'-UTR region of cyclin D1 [67-69]. Although, no experimental data is available to date about the interaction of miR-497-CCND1 in colorectal cancer, the overexpression of cyclin D1 mRNA might cause by the underexpression of miR-497 in colorectal adenoma and cancer by posttranscriptional silencing. Further investigations would confirmed our hypothesis."

\section{Conclusion}

We report here a study of the levels of 1733 mature miRNA in healthy, adenoma and colorectal cancer samples by two different methods. Besides the previously described miRNAs in pre- and neoplastic lesions, we also identified new, less known miRNAs (miR-4417), with altered expression in different colorectal neoplastic alterations. Our data also showed that tissue miRNA expression alterations could be observed also in plasma and may serve as valuable early diagnostic markers. Analysis of miRNA expression and predicted target mRNA was performed from the same patient set. Negative correlations were observed between miRNAs and targeted mRNAs, which could be explored further in functional analysis of neoplastic development related alterations. 


\section{Additional files}

Additional file 1: Clinicopathological features of 60 patients.
(DOCX $18 \mathrm{~kb}$ )

Additional file 2: Detailed LogFC values between patient groups. (DOCX $24 \mathrm{~kb}$ )

Additional file 3: $\mathrm{KEGG}$ and $\mathrm{GO}$ analyses of the selected miRNAs. (DOCX $27 \mathrm{~kb}$ )

\section{Abbreviations}

ABHD2: Abhydrolase domain containing 2; ACAA2: Acetyl-CoA acyltransferase 2; ADtub/ADT: Tubular adenoma; ADtubvill/ ADTV: Tubulovillous adenoma; ANXA1: Annexin 1; AXIN2: Axin 2; CALU: Calumenin; CCND1: Cyclin D1; CDK4: Cyclin dependent kinase 4; CDKN2B: Cyclin dependent kinase inhibitor 2B; CDKN2b: Cyclin-dependent kinase inhibitor 2B; CEP55: Centrosomal protein 55; CES2: Carboxylesterase 2; CRC/C: Colorectal cancer; DNAJC10: DnaJ heat shock protein family (Hsp40) member C10; E2F3: E2F transcription factor 3; FF: Fresh frozen; FFPET: Formalin-fixed, paraffin-embedded tissue; FMO4: Flavin containing monooxygenase 4; FSCN1: Fascin actin-bundling protein 1; GPRC5A: G protein-coupled receptor class $C$ group 5 member A; ITGA2: Integrin subunit alpha 2; KIF5B: Kinesin family member 5B; L1CAM: L1 adhesion molecule; LIM: Lin11/IsI1/Mec3; miRNA: microRNA; N: Normal; NR5A2: Nuclear receptor subfamily 5 group A member 2; OSBPL3: Oxysterol binding protein like 3; PDE3A: Phosphodiesterase 3A; PPIL1: Peptidylprolyl isomerase like 1; PSAT1: Phosphoserine aminotransferase 1; PTGDR: Prostaglandin D2 receptor; RMA: Robust multichip averaging; RTN4: Reticulon 4; SESTD1: SEC14 and spectrin domain containing 1; SH3: SRC homology 3 domain; SNRPB2: Small nuclear ribonucleoprotein polypeptide B2; ST6GALNAC6: ST6 Nacetylgalactosaminide alpha-2,6-sialyltransferase 6; TESK2: Testis-specific kinase 2; TRANK1: Tetratricopeptide repeat and ankyrin repeat containing 1; UBE2H: Ubiquitin conjugating enzyme E2 H; ZNF391: Zinc finger protein 391

\section{Acknowledgements}

The collection of patient data used in this study was supported by the 2nd Department of Internal Medicine, Semmelweis University. Authors gratefully thank Bernadett Tóth (2nd Department of Internal Medicine, Semmelweis University) for her technical assistance in sample collection and data administration. The authors would like to thank Theo deVos for language revision of the manuscript.

\section{Funding}

This study was supported by the National Research, Development and Innovation Office (KMR-12-1-2012-0216 grant).

\section{Availability of data and materials}

The datasets generated and analyzed during the current study are available on Gene Expression Omnibus (GEO) data repository: GEO ID: GSE83924(http://www.ncbi.nlm.nih.gov/geo/query/acc.cgi?acc=GSE83924).

\section{Authors' contribution}

ZBN, AK, and BKB isolated RNA from tissue and plasma samples; ZBN performed the microarray experiments; BW and SS conducted bioinformatic analyses; OG, ZST, and BM contributed to the design and critical review of the manuscript. All authors read and approved the final manuscript.

\section{Competing interests}

The authors declare that they have no competing interests.

\section{Consent for publication}

Not applicable.

\section{Ethics approval and consent to participate}

The study protocol was approved by the local ethics committee (Semmelweis University Regional and Institutional Committee of Science and Research Ethics; Nr.: ETT TUKEB 23970/2011), and written informed consent was provided by all patients.

\section{Author details}

Molecular Gastroenterology Laboratory, 2nd Department of Internal Medicine, Semmelweis University, Szentkirályi Str. 46, Budapest 1088, Hungary. ${ }^{2}$ Molecular Medicine Research Group, Hungarian Academy of Sciences, Budapest, Hungary. ${ }^{3}$ Current Address: Department of Medical Oncology, Dana-Farber Cancer Institute, Boston, MA, USA.

Received: 25 June 2016 Accepted: 19 December 2016

Published online: 14 February 2017

\section{References}

1. Jemal A, Siegel R, Xu J, Ward E. Cancer statistics, 2010. CA Cancer J Clin. 2010;60(5):277-300

2. Fearon ER, Vogelstein B. A genetic model for colorectal tumorigenesis. Cell. 1990;61(5):759-67.

3. Slattery ML, Herrick JS, Pellatt DF, Stevens JR, Mullany LE, Wolff E, Hoffman MD, Samowitz WS, Wolff RK. MicroRNA profiles in colorectal carcinomas, adenomas and normal colonic mucosa: variations in miRNA expression and disease progression. Carcinogenesis. 2016;37(3):245-61.

4. Bartley AN, Yao H, Barkoh BA, Ivan C, Mishra BM, Rashid A, Calin GA, Luthra R, Hamilton SR. Complex Patterns of Altered MicroRNA Expression during the Adenoma-Adenocarcinoma Sequence for Microsatellite-Stable Colorectal Cancer. Clin Cancer Res. 2011;17(23):7283-7293.

5. Kinzler KW, Vogelstein B. Lessons from hereditary colorectal cancer. Cell. 1996;87(2):159-70

6. Muzny DM, Bainbridge MN, Chang K, Dinh HH, Drummond JA, Fowler G, Kovar CL, Lewis LR, Morgan MB, Newsham IF, et al. Comprehensive molecular characterization of human colon and rectal cancer. Nature. 2012; 487(7407):330-7.

7. Shastri YM, Loitsch S, Hoepffner N, Povse N, Hanisch E, Rosch W, Mossner J, Stein JM. Comparison of an established simple office-based immunological FOBT with fecal tumor pyruvate kinase type M2 (M2-PK) for colorectal cancer screening: Prospective multicenter study. Am J Gastroenterol. 2008; 103(6):1496-504

8. Ahlquist DA. Molecular detection of colorectal neoplasia. Gastroenterology. 2010;138(6):2127-39

9. Takai T, Kanaoka S, Yoshida K, Hamaya Y, Ikuma M, Miura N, Sugimura H, Kajimura M, Hishida A. Fecal cyclooxygenase 2 plus matrix metalloproteinase 7 mRNA assays as a marker for colorectal cancer screening. Cancer Epidem Biomar. 2009;18(6):1888-93.

10. Wu CW, Ng SS, Dong YJ, Ng SC, Leung WW, Lee CW, Wong YN, Chan FK, Yu J, Sung JJ. Detection of miR-92a and miR-21 in stool samples as potential screening biomarkers for colorectal cancer and polyps. Gut. 2012; 61(5):739-45.

11. Bartel DP. MicroRNAs: target recognition and regulatory functions. Cell. 2009;136(2):215-33.

12. Iorio MV, Ferracin M, Liu CG, Veronese A, Spizzo R, Sabbioni S, Magri E, Pedriali M, Fabbri M, Campiglio M, et al. MicroRNA gene expression deregulation in human breast cancer. Cancer Res. 2005;65(16):7065-70.

13. Murakami Y, Yasuda T, Saigo K, Urashima T, Toyoda H, Okanoue T, Shimotohno K. Comprehensive analysis of microRNA expression patterns in hepatocellular carcinoma and non-tumorous tissues. Oncogene. 2006;25(17): 2537-45.

14. Cummins JM, He Y, Leary RJ, Pagliarini R, Diaz Jr LA, Sjoblom T, Barad O, Bentwich Z, Szafranska AE, Labourier E, et al. The colorectal microRNAome. Proc Natl Acad Sci U S A. 2006:103(10):3687-92.

15. Yanaihara N, Caplen N, Bowman E, Seike M, Kumamoto K, Yi M, Stephens RM, Okamoto A, Yokota J, Tanaka T, et al. Unique microRNA molecular profiles in lung cancer diagnosis and prognosis. Cancer Cell. 2006;9(3):189-98.

16. Schetter AJ, Leung SY, Sohn JJ, Zanetti KA, Bowman ED, Yanaihara N, Yuen ST, Chan TL, Kwong DL, Au GK, et al. MicroRNA expression profiles associated with prognosis and therapeutic outcome in colon adenocarcinoma. JAMA. 2008;299(4):425-36.

17. Hibino Y, Sakamoto N, Naito Y, Goto K, Oo HZ, Sentani K, Hinoi T, Ohdan H, Oue N, Yasui W. Significance of miR-148a in colorectal neoplasia: downregulation of miR-148a contributes to the carcinogenesis and cell invasion of colorectal cancer. Pathobiology. 2015;82(5):233-41.

18. Sethupathy $P$, Megraw M, Hatzigeorgiou AG. A guide through present computational approaches for the identification of mammalian microRNA targets. Nat Methods. 2006;3(11):881-6. 
19. Ruan J, Chen H, Kurgan L, Chen K, Kang C, Pu P. HuMiTar: a sequence-based method for prediction of human microRNA targets. Algorithms Mol Biol. 2008;3:16.

20. Yue D, Liu H, Huang Y. Survey of computational algorithms for microRNA target prediction. Curr Genomics. 2009;10(7):478-92.

21. Papadopoulos GL, Reczko M, Simossis VA, Sethupathy P, Hatzigeorgiou AG. The database of experimentally supported targets: a functional update of TarBase. Nucleic Acids Res. 2009;37(Database issue):D155-158.

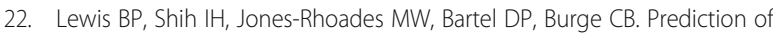
mammalian microRNA targets. Cell. 2003;115(7):787-98.

23. Mitchell PS, Parkin RK, Kroh EM, Fritz BR, Wyman SK, Pogosova-Agadjanyan EL, Peterson A, Noteboom J, O'Briant KC, Allen A, et al. Circulating microRNAs as stable blood-based markers for cancer detection. Proc Natl Acad Sci U S A. 2008;105(30):10513-8.

24. Zou TT, Selaru FM, Xu Y, Shustova V, Yin J, Mori Y, Shibata D, Sato F, Wang $\mathrm{S}$, Olaru A, et al. Application of cDNA microarrays to generate a molecular taxonomy capable of distinguishing between colon cancer and normal colon. Oncogene. 2002;21(31):4855-62.

25. Balaguer F, Moreira L, Lozano JJ, Link A, Ramirez G, Shen Y, Cuatrecasas M, Arnold M, Meltzer SJ, Syngal S, et al. Colorectal cancers with microsatellite instability display unique miRNA profiles. Clin Cancer Res. 2011;17(19):6239-49.

26. Chen X, Guo X, Zhang H, Xiang Y, Chen J, Yin Y, Cai X, Wang K, Wang G, Ba $Y$, et al. Role of miR-143 targeting KRAS in colorectal tumorigenesis. Oncogene. 2009;28(10):1385-92.

27. Patai AV, Valcz G, Hollosi P, Kalmar A, Peterfia B, Patai A, Wichmann B, Spisak S, Bartak BK, Leiszter K, et al. Comprehensive DNA methylation analysis reveals a common ten-gene methylation signature in colorectal adenomas and carcinomas. PLoS One. 2015;10(8):e0133836.

28. Galamb O, Spisak S, Sipos F, Toth K, Solymosi N, Wichmann B, Krenacs T, Valcz G, Tulassay Z, Molnar B. Reversal of gene expression changes in the colorectal normal-adenoma pathway by NS398 selective COX2 inhibitor. Brit J Cancer. 2010;102(4):765-73.

29. Galamb O, Sipos F, Solymosi N, Spisak S, Krenacs T, Toth K, Tulassay Z, Molnar B. Diagnostic mRNA expression patterns of inflamed, benign, and malignant colorectal biopsy specimen and their correlation with peripheral blood results. Cancer Epidem Biomar. 2008;17(10):2835-45.

30. Galamb O, Gyorffy B, Sipos F, Spisaka S, Nemetha AM, Mihellera P, Tulassay Z, Dinya E, Molnar B. Inflammation, adenoma and cancer: objective classification of colon biopsy specimens with gene expression signature. Dis Markers. 2008;25(1):1-16.

31. Spisak S, Galamb B, Sipos F, Galamb O, Wichmann B, Solymosi N, Nemes B, Molnar J, Tulassay Z, Molnar B. Applicability of antibody and mRNA expression microarrays for identifying diagnostic and progression markers of early and late stage colorectal cancer. Dis Markers. 2010;28(1):1-14.

32. Toth K, Wasserkort R, Sipos F, Kalmar A, Wichmann B, Leiszter K, Valcz G, Juhasz M, Miheller P, Patai AV, et al. Detection of methylated septin 9 in tissue and plasma of colorectal patients with neoplasia and the relationship to the amount of circulating cell-free DNA. PLoS One. 2014; 9(12):e115415.

33. Livak KJ, Schmittgen TD. Analysis of relative gene expression data using real-time quantitative PCR and the 2(T)(-Delta Delta C) method. Methods. 2001;25(4):402-8

34. Yin Y, Song M, Gu B, Qi X, Hu Y, Feng Y, Liu H, Zhou L, Bian Z, Zhang J, et al. Systematic analysis of key miRNAs and related signaling pathways in colorectal tumorigenesis. Gene. 2016:578(2):177-84.

35. Leidinger P, Galata V, Backes C, Stahler C, Rheinheimer S, Huwer H, Meese E, Keller A. Longitudinal study on circulating miRNAs in patients after lung cancer resection. Oncotarget. 2015;6(18):16674-85.

36. Gattolliat $\mathrm{CH}$, Uguen A, Pesson M, Trillet $\mathrm{K}$, Simon B, Doucet $\mathrm{L}$, Robaszkiewicz M, Corcos L. MicroRNA and targeted mRNA expression profiling analysis in human colorectal adenomas and adenocarcinomas. Eur J Cancer. 2015;51(3):409-20.

37. Murria Estal R, Palanca Suela S, de Juan Jl, Alenda Gonzalez C, Egoavil Rojas C, Garcia-Casado Z, Lopez Guerrero JA, Juan Fita MJ, Sanchez Heras AB, Segura Huerta A, et al. Relationship of immunohistochemistry, copy number aberrations and epigenetic disorders with BRCAness pattern in hereditary and sporadic breast cancer. Familial Cancer. 2016;15(2):193-200.

38. Chang KH, Miller N, Kheirelseid EA, Lemetre C, Ball GR, Smith MJ, Regan M, McAnena OJ, Kerin MJ. MicroRNA signature analysis in colorectal cancer: identification of expression profiles in stage II tumors associated with aggressive disease. Int J Color Dis. 2011;26(11):1415-22.
39. Zhang GJ, Zhou H, Xiao HX, Li Y, Zhou T. MiR-378 is an independent prognostic factor and inhibits cell growth and invasion in colorectal cancer. BMC cancer. 2014;14:109-118.

40. Tanoglu A, Balta AZ, Berber U, Ozdemir Y, Emirzeoglu L, Sayilir A, Sucullu I. MicroRNA expression profile in patients with stage II colorectal cancer: a Turkish referral center study. Asian Pac J Cancer Prev. 2015;16(5):1851-5.

41. Zheng K, Liu W, Liu Y, Jiang C, Qian Q. MicroRNA-133a suppresses colorectal cancer cell invasion by targeting Fascin1. Oncol Lett. 2015;9(2):869-74.

42. Wang LL, Du LT, Li J, Liu YM, Qu AL, Yang YM, Zhang X, Zheng GX, Wang CX. Decreased expression of miR-133a correlates with poor prognosis in colorectal cancer patients. World J Gastroenterol. 2014;20(32):11340-6.

43. Wang $H$, An H, Wang B, Liao Q, Li W, Jin X, Cui S, Zhang Y, Ding Y, Zhao L. miR-133a represses tumour growth and metastasis in colorectal cancer by targeting LIM and SH3 protein 1 and inhibiting the MAPK pathway. Eur J Cancer. 2013;49(18):3924-35.

44. Faltejskova P, Svoboda M, Srutova K, Mlcochova J, Besse A, Nekvindova J, Radova L, Fabian P, Slaba K, Kiss I, et al. Identification and functional screening of microRNAs highly deregulated in colorectal cancer. J Cell Mol Med. 2012;16(11):2655-66.

45. Liu H, Song Z, Liao DG, Zhang TY, Liu F, Zheng W, Luo K, Yang L. miR-503 inhibits cell proliferation and invasion in glioma by targeting L1CAM. Int J Clin Exp Med. 2015;8(10):18441-7.

46. Chang SW, Yue J, Wang BC, Zhang XL. miR-503 inhibits cell proliferation and induces apoptosis in colorectal cancer cells by targeting E2F3. Int J Clin Exp Pathol. 2015;8(10):12853-60.

47. Wang $X$, Chen L, Jin H, Wang S, Zhang Y, Tang X, Tang G. Screening miRNAs for early diagnosis of colorectal cancer by small RNA deep sequencing and evaluation in a Chinese patient population. OncoTargets Ther. 2016;9:1159-66.

48. Perilli L, Vicentini C, Agostini M, Pizzini S, Pizzi M, D’Angelo E, Bortoluzzi S, Mandruzzato S, Mammano E, Rugge M, et al. Circulating miR-182 is a biomarker of colorectal adenocarcinoma progression. Oncotarget. 2014; 5(16):6611-9.

49. Pizzini S, Bisognin A, Mandruzzato S, Biasiolo M, Facciolli A, Perilli L, Rossi E, Esposito G, Rugge M, Pilati $P$, et al. Impact of microRNAs on regulatory networks and pathways in human colorectal carcinogenesis and development of metastasis. BMC Genomics. 2013;14:589.

50. Zhang HH, Gu GL, Zhang XY, Li FZ, Ding L, Fan Q, Wu R, Shi W, Wang $X Y$, Chen $L$, et al. Primary analysis and screening of microRNAs in gastric cancer side population cells. World J Gastroenterol. 2015;21(12): 3519-26

51. Schopman NC, Heynen S, Haasnoot J, Berkhout B. A miRNA-tRNA mix-up: tRNA origin of proposed miRNA. RNA Biol. 2010;7(5):573-6.

52. Nonaka R, Miyake Y, Hata T, Kagawa Y, Kato T, Osawa H, Nishimura J, Ikenaga M, Murata K, Uemura M, et al. Circulating miR-103 and miR-720 as novel serum biomarkers for patients with colorectal cancer. Int J Oncol. 2015;47(3):1097-102

53. Kikkawa N, Hanazawa T, Fujimura L, Nohata N, Suzuki H, Chazono H, Sakurai D, Horiguchi S, Okamoto Y, Seki N. miR-489 is a tumour-suppressive miRNA target PTPN11 in hypopharyngeal squamous cell carcinoma (HSCC). Brit J Cancer. 2010;103(6):877-84

54. Jiang L, He DX, Yang DT, Chen Z, Pan QX, Mao AQ, Cai YF, Li XY, Xing H, Shi $\mathrm{M}$, et al. MiR-489 regulates chemoresistance in breast cancer via epithelial mesenchymal transition pathway. Febs Lett. 2014;588(11):2009-15.

55. Wang FF, Zhang XJ, Yan YR, Zhu XH, Yu J, Ding Y, Hu JL, Zhou WJ, Zeng ZC, Liao WT, et al. FBX8 is a metastasis suppressor downstream of miR-223 and targeting mTOR for degradation in colorectal cancer. Cancer letters. 2017; 388:85-95.

56. Zhao J, Lei T, Xu C, Li H, Ma W, Yang Y, Fan S, Liu Y. MicroRNA-187, downregulated in clear cell renal cell carcinoma and associated with lower survival, inhibits cell growth and migration though targeting B7- $\mathrm{H3}$. Biochem Biophys Res Commun. 2013;438(2):439-44.

57. Wang CJ, Zhou ZG, Wang L, Yang L, Zhou B, Gu J, Chen HY, Sun XF. Clinicopathological significance of microRNA-31, -143 and -145 expression in colorectal cancer. Dis Markers. 2009;26(1):27-34

58. Slaby O, Svoboda M, Fabian P, Smerdova T, Knoflickova D, Bednarikova M, Nenutil R, Vyzula R. Altered expression of miR-21, miR-31, miR-143 and miR145 is related to clinicopathologic features of colorectal cancer. Oncology Basel. 2007;72(5-6):397-402.

59. Hernandez D, Janmohamed A Chandan P, Phillips IR, Shephard EA. Organization and evolution of the flavin-containing monooxygenase genes 
of human and mouse: identification of novel gene and pseudogene clusters. Pharmacogenetics. 2004;14(2):117-30.

60. Kalmar A, Peterfia B, Hollosi P, Galamb O, Spisak S, Wichmann B, Bodor A, Toth K, Patai AV, Valcz G, et al. DNA hypermethylation and decreased mRNA expression of MAL, PRIMA1, PTGDR and SFRP1 in colorectal adenoma and cancer. BMC Cancer. 2015;15:736.

61. Zhang N, Shen Q, Zhang P. miR-497 suppresses epithelial-mesenchymal transition and metastasis in colorectal cancer cells by targeting fos-related antigen-1. OncoTargets Ther. 2016;9:6597-604.

62. Li W, Jin X, Deng X, Zhang G, Zhang B, Ma L. The putative tumor suppressor microRNA-497 modulates gastric cancer cell proliferation and invasion by repressing elF4E. Biochem Biophys Res Commun. 2014;449(2):235-40.

63. Du M, Shi D, Yuan L, Li P, Chu H, Qin C, Yin C, Zhang Z, Wang M. Circulating miR-497 and miR-663b in plasma are potential novel biomarkers for bladder cancer. Sci Rep. 2015:5:10437.

64. Xu T, Zhu Y, Xiong Y, Ge YY, Yun JP, Zhuang SM. MicroRNA-195 suppresses tumorigenicity and regulates $\mathrm{G} 1 / \mathrm{S}$ transition of human hepatocellular carcinoma cells. Hepatology. 2009;50(1):113-21.

65. Lehmann U, Streichert T, Otto B, Albat C, Hasemeier B, Christgen H, Schipper E, Hille U, Kreipe HH, Langer F. Identification of differentially expressed microRNAs in human male breast cancer. BMC Cancer. 2010;10:109.

66. Tarasov VA, Matishov DG, Shin EF, Boiko NV, Timoshkina NN, Makhotkin MA, Lomonosov AM, Kirpii AA, Kit Ol, Maksimov AY. Coordinated aberranit expression of miRNAs in colon cancer. Genetika. 2014;50(10):1232-44.

67. Li D, Zhao Y, Liu C, Chen X, Qi Y, Jiang Y, Zou C, Zhang X, Liu S, Wang X, et al. Analysis of MiR-195 and MiR-497 expression, regulation and role in breast cancer. Clin Cancer Res. 2011;17(7):1722-30.

68. Hui W, Yuntao L, Lun L, WenSheng L, ChaoFeng L, HaiYong H, Yueyang B. MicroRNA-195 inhibits the proliferation of human glioma cells by directly targeting cyclin D1 and cyclin E1. PLoS One. 2013;8(1):e54932.

69. Han K, Chen X, Bian N, Ma B, Yang T, Cai C, Fan Q, Zhou Y, Zhao TB. MicroRNA profiling identifies MiR-195 suppresses osteosarcoma cell metastasis by targeting CCND1. Oncotarget. 2015;6(11):8875-89.

\section{Submit your next manuscript to BioMed Central and we will help you at every step:}

- We accept pre-submission inquiries

- Our selector tool helps you to find the most relevant journal

- We provide round the clock customer support

- Convenient online submission

- Thorough peer review

- Inclusion in PubMed and all major indexing services

- Maximum visibility for your research

Submit your manuscript at www.biomedcentral.com/submit 